\title{
Effect of milrinone on the inflammatory response and NF-kB activation in renal ischemia-reperfusion injury in mice
}

\author{
Hong Soo Jung ${ }^{1}$, Jin-Deok Joo ${ }^{1}$, Dae-Woo Kim ${ }^{1}$, Jang Hyeok $\mathrm{In}^{1}$, Misun Roh ${ }^{1}$, Jong-Tae Jeong ${ }^{1}$, \\ Seung June $\mathrm{Noh}^{2}$, and Jin Woo Choi ${ }^{1}$ \\ ${ }^{1}$ Department of Anesthesiology and Pain Medicine, College of Medicine, ${ }^{2}$ The Research Institute of Medical Science, St. Vincent's \\ Hospital, The Catholic University of Korea, Suwon, Korea
}

Background: Milrinone increases intracellular adenosine 3',5'-cyclic monophosphate concentration and enhances vascular relaxation. Nuclear factor-kappa B (NF-kB) plays a key role in inflammatory responses during ischemia-reperfusion (I/R) injury. We aimed to investigate the effect of milrinone on the inflammatory responses and NF-kB activation in renal I/R injury in mice.

Methods: Thirty C57BL/6 mice were allocated into 3 groups. In group S $(\mathrm{n}=10)$, only right nephrectomy was done. In group C ( $\mathrm{n}=10)$, the left kidney was subjected to $30 \mathrm{~min}$ of ischemia after right nephrectomy. In group $\mathrm{M}(\mathrm{n}=10)$, milrinone $(5 \mu \mathrm{g} / \mathrm{kg})$ was administered before ischemia. After 24 hours of reperfusion, the serum creatinine was measured, kidney samples were obtained for histology, and expressions of NF-kB and proinflammatory cytokines were analyzed.

Results: In group C, the serum creatinine concentration was markedly elevated, compared with group S. Creatinine concentration in group $\mathrm{M}$ was also elevated, but it was significantly lower than that in group $\mathrm{C}$. Histologic evidence of renal damage was severe in group $C$, but it was improved in group $M$. In groups $C$ and $M$, expression of NF-kB, tumor necrosis factor- $\alpha$ (TNF- $\alpha$ ), intercellular adhesion molecule-1 (ICAM-1), monocyte chemoattractant protein-1 (MCP-1) and macrophage inflammatory protein-2 (MIP-2) mRNA increased significantly compared with group $\mathrm{S}(\mathrm{P}<0.05)$. But group $\mathrm{M}$ showed a lower expression of NF-kB, TNF- $\alpha$, ICAM-1, MCP-1 and MIP-2 mRNA than group C $(\mathrm{P}<0.05)$.

Conclusions: Milrinone treatment attenuates the renal inflammatory response and activation of NF-kB, resulting in improvement of renal function and tissue injury. (Korean J Anesthesiol 2014; 66: 136-142)

Key Words: Ischemia-reperfusion injury, Milrinone, Nuclear-factor-kappa B.

Received: July 16, 2013. Revised: 1st, August 12, 2013; 2nd, October 1, 2013; 3rd, October 10, 2013; 4th, October 15, 2013. Accepted: October 16, 2013. Corresponding author: Jin Woo Choi, M.D., Ph.D., Department of Anesthesiology and Pain Medicine, College of Medicine, The Catholic University of Korea, Ji-dong, Paldal-gu, Suwon 442-723, Korea. Tel: 82-31-249-7212, Fax: 82-31-258-4212, E-mail: cjwooo@catholic.ac.kr (c) This is an open-access article distributed under the terms of the Creative Commons Attribution Non-Commercial License (http:// creativecommons.org/licenses/by-nc/3.0/), which permits unrestricted non-commercial use, distribution, and reproduction in any medium, provided the original work is properly cited. 


\section{Introduction}

Renal ischemia-reperfusion (I/R) injury, which causes acute renal failure (ARF), still remains a serious clinical issue in $a b-$ dominal aortic surgery and in kidney transplantations because it is a major cause of mortality and morbidity during the perioperative period. Many studies such as those on ischemic-preconditioning, pretreatment with adenosine, preconditioning with a volatile agent, and activation of adenosine-monophosphateactivated protein kinase (AMPK) have been done to find factors that protect against renal I/R injury. Recent studies suggest that $\mathrm{I} / \mathrm{R}$ injury is closely related to the activation of adenosine receptors, which causes protective effects against I/R injury by activation of signal-transduction proteins such as Akt, extracellular signal-regulated kinase (ERK), heat shock protein 27 (HSP 27), HSP 70, inducible nitric oxide (iNOS) [1].

Nuclear factor-kappa B (NF-kB) is a key transcription factor in the regulation of the acute inflammatory response, which plays a key role in I/R injury [2]. NF-kB exists in the cytoplasm as heterodimers bound to inhibitory proteins known as inhibitors of NF-kB (IkBs) [3]. Inflammatory cytokines such as tumor necrosis factor (TNF)- $\alpha$ induce the phosphorylation and subsequent degradation of IkBs [4], which liberates NF-kB to enter the nucleus and activates NF-kB induced target genes [5].

Milrinone is a selective phosphodiesterase-3 (PDE-3) inhibitor, which suppresses the degradation process of adenosine 3', ' '-cyclic monophosphate (cAMP), resulting in an increase of the intracellular concentration of cAMP. Because milrinone increases myocardial contractility and enhances vascular muscle relaxation, it has been used clinically in the treatment of congestive heart failure [6]. Moreover, it is reported that milrinone has an anti-inflammatory effect [7], which is expected to reduce I/R injury. Although the protective effects of milrinone against renal I/R injury were reported [8], the molecular mechanism has not been clearly found. The aim of the present study is to investigate the effect of milrinone on the inflammatory responses and NF$\mathrm{kB}$ activation in renal $\mathrm{I} / \mathrm{R}$ injury in mice.

\section{Materials and Methods}

\section{Renal I/R injury and milrinone treatment}

The experiments were approved by the Institutional Laboratory Animal Care and the Ethical Committee. C57BL/6 mice ( 20 to $25 \mathrm{~g}$ ), aged from 8 to 10 weeks, were anesthetized with intraperitoneally administered pentobarbital sodium $(50 \mathrm{mg} / \mathrm{kg}$ or to effect) and placed supine on a heating pad under a warming light to maintain body temperature between 36 and $38^{\circ} \mathrm{C}$. Additional pentobarbital sodium was given as needed based on responses to tail pinches. Thirty mice were randomly allocated to the following three groups. In group $\mathrm{C}(\mathrm{n}=10$, control group), after bilateral flank incisions and after right nephrectomy, the left kidney was subjected to $30 \mathrm{~min}$ of ischemia with a microaneurysm clip occluding the renal pedicle. In group $M(n=10$, milrinone treatment group), in accordance with the clinical dose applied for the treatment of acute heart failure, $5 \mu \mathrm{g} / \mathrm{kg}$ of milrinone was injected by bolus intraperitoneally before renal ischemia. In group $S$ ( $n=10$, sham operation group), mice were anesthetized and subjected to right nephrectomy only, and plasma was collected 24 hours later. In groups C and M, after 30 min of ischemia, the microaneurysm clip was removed for reperfusion, and after 24 hours, plasma was collected and the mice were subjected to left nephrectomy to acquire their kidney tissues.

\section{Assessment of renal function after I/R injury}

Renal function was assessed by measuring plasma creatinine concentrations $24 \mathrm{~h}$ after renal ischemia, with a commercially available colorimetric method (Sigma, St. Louis, USA).

\section{Histologic examinations to detect necrosis}

Explanted kidneys were bisected along the long axis and were fixed with $10 \%$ formalin, embedded in paraffin, cut into $5 \mu \mathrm{m}$ sections, and stained with hematoxylin-eosin (H\&E). All microscopic slides were analyzed by a pathologist blinded to the group assignments of the animals. A grading scale of 0 to 4 , as outlined by Jablonski et al. [9], was used to assess the renal histological injury.

\section{Semiquantitative reverse transcription-polymerase chain reaction ( $R T-P C R$ )}

Twenty-four hours after renal ischemic injury, the kidney tissues were dissected, and the total RNA was extracted using a Trizol kit (Invitrogen, Carlsbad, CA, USA). Total RNA concentrations were determined by spectrophotometric absorbance at $260 \mathrm{~nm}$, and aliquots were analyzed by agarose gel electrophoresis to verify equal RNA inputs and RNA quality. RT-PCR was performed to analyze the expression of proinflammatory (TNF- $\alpha$, intercellular adhesion molecule-1 [ICAM-1], monocyte chemoattractant protein-1 [MCP-1], macrophage inflammatory protein-2 [MIP-2]) genes. Primers were designed based on published GenBank sequences for the mouse (Table 1).

\section{NF-kB assay}

Kidney tissues were dissected on ice and immediately placed in an ice-cold radioimmunoprecipitation assay (RIPA) buffer (150 mM NaCl, 50 mM Tris-HCl, 1 mM EDTA, and 1\% Triton-X 
Table 1. Primer Sequences

\begin{tabular}{clclc}
\hline Primers & Species & Size, bp & \multicolumn{1}{c}{$\begin{array}{c}\text { Sequence (5'-3') } \\
\text { PCR, Temp. } \\
{ }^{\circ} \text { C/Cyc. }\end{array}$} \\
\hline TNF- $\alpha$ & Mouse & 290 & $\begin{array}{l}\text { TACTGAACTTCGGGGTGATTGGTCC } \\
\text { CAGCCTTGTCCCTTGAAGAGAACC } \\
\text { TCTTTCCTGCCTCTGAAGC }\end{array}$ & $60 / 35$ \\
ICAM-1 & Mouse & 409 & $\begin{array}{l}\text { CTTCGTTGTGATCCTCCG } \\
\text { ACCTGCTGCTACTCATTCAC }\end{array}$ & $60 / 35$ \\
MCP-1 & Mouse & 312 & $\begin{array}{l}\text { TTGAGGTGGTTGTGGAAAAG } \\
\text { CCAAGGGTTGACTTCAAGAAC }\end{array}$ & $60 / 35$ \\
MIP-2 & Mouse & 282 & $\begin{array}{l}\text { AGCGAGGCACATCAGGTACG } \\
\text { ACCACAGTCCATGCCATCAC }\end{array}$ & $60 / 35$ \\
GAPDH & Mouse & 450 & CACCACCCTGTTGCTGTAGCC & $60 / 35$ \\
& & &
\end{tabular}

TNF- $\alpha$ : tumor necrosis factor- $\alpha$, ICAM-1: intercellular adhesion molecule-1, MCP-1: monocyte chemoattractant protein-1, MIP-2: macrophage inflammatory protein-2, GAPDH: glyceraldehyde 3-phosphate dehydrogenase.

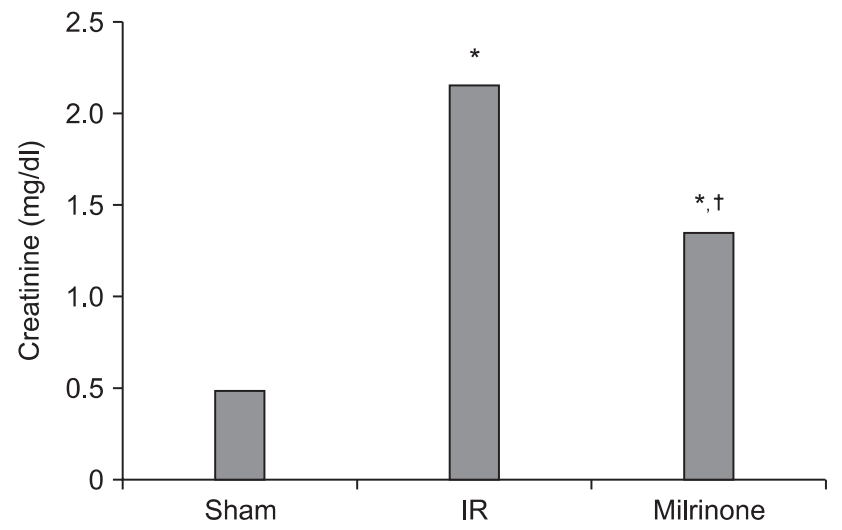

Fig. 1. Comparison of mean serum creatinine concentration (sham, group $\mathrm{S}$; IR, group C; Milrinone, group $\mathrm{M}) . * \mathrm{P}<0.001$ vs. group $\mathrm{S} .{ }^{\dagger} \mathrm{P}<0.001$ vs. group C.

[pH 7.4]) and homogenized for $10 \mathrm{~s}$ on ice. The samples were centrifuged for $30 \mathrm{~min}$ at $50000 \mathrm{~g}$. The supernatant was collected and used for immunoblotting. We measured the expression of NF-kB.

\section{Statistical analysis}

All data were expressed as the means \pm standard deviations. One-way analysis of variance (ANOVA) with the Tukey post hoc test was used to compare quantitative variables between the groups, and a P value of less than 0.05 was considered statistically significant. Statistical analyses were performed using SPSS version 18.0 (SPSS Inc., Chicago, IL, USA).

\section{Results}

\section{Renal function}

In group $\mathrm{C}$, serum creatinine concentration after 24 hours reperfusion was markedly elevated compared with group $S$ (2.17 \pm 0.24 vs. $0.50 \pm 0.14, \mathrm{P}<0.001)$. The serum concentration of creatinine in group $\mathrm{M}$ was also elevated (1.36 \pm 0.37 vs. $0.50 \pm$ $0.14, \mathrm{P}<0.001)$, but it was significantly lower than that in group $\mathrm{C}(1.36 \pm 0.37$ vs. $2.17 \pm 0.24, \mathrm{P}<0.001)$ (Fig. 1$)$.

\section{Histological changes}

Histological findings showed significant renal injury as evidenced by severe necrosis of the proximal convoluted tubule, tubular lumen obstruction and impairments, desquamation of tubule cells, severe medullary congestion and hemorrhage in group C. These renal injury findings were improved in group $\mathrm{M}$, compared with group C (Fig. 2). The Jablonski scale histology grading scores are shown in Fig. 3.

\section{Expression of pro-inflammatory cytokines}

In groups $\mathrm{C}$ and $\mathrm{M}$, expression of TNF- $\alpha$, ICAM-1, MCP-1 and MIP-2 mRNA increased significantly compared with group $\mathrm{S}(\mathrm{P}<0.001)$. But group $\mathrm{M}$ showed a lower expression of TNF- $\alpha$, ICAM-1, MCP-1 and MIP-2 mRNA than group C $(\mathrm{P}<0.001)$ (Fig. 4).

\section{NF-kB activity}

The NF-kB level increased in groups $\mathrm{C}$ and $\mathrm{M}$ compared with group $\mathrm{S}(\mathrm{P}<0.001)$. However, the $\mathrm{NF}-\mathrm{kB}$ level in group $\mathrm{M}$ was significantly lower than that in group $\mathrm{C}(\mathrm{P}<0.001)$ (Fig. 5).

\section{Disccussion}

Milrinone inhibits PDE-3, which degrades c-AMP, resulting in an increase of intracellular c-AMP concentration. Additionally, in vascular smooth muscle, it leads to vasodilation of 

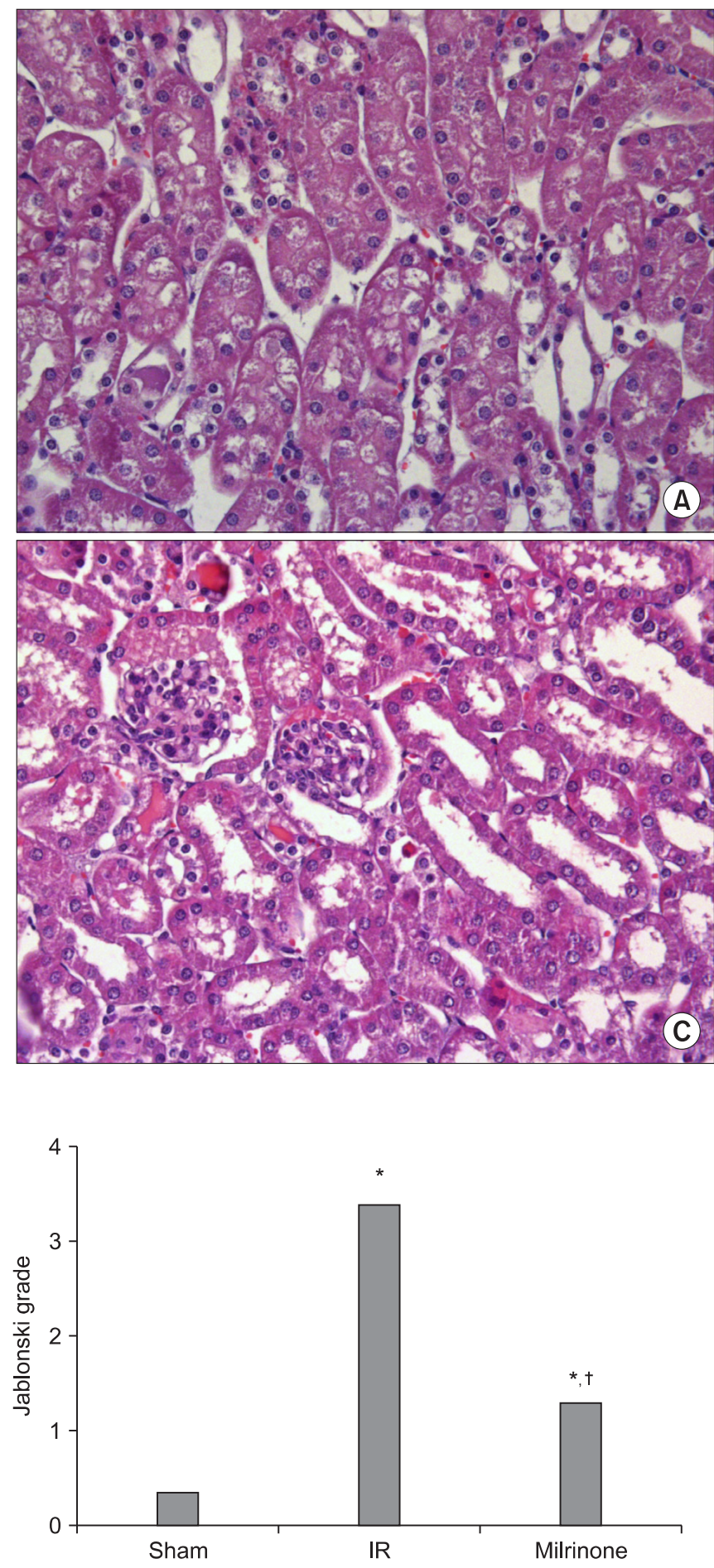

Fig. 3. Jablonski grading scale scores (sham, group $S, n=10$; IR, group $C$, $\mathrm{n}=10$; milrinone, group $\mathrm{M}, \mathrm{n}=10) .{ }^{*} \mathrm{P}<0.001$ vs. group $\mathrm{S} .{ }^{\dagger} \mathrm{P}<0.001$ vs. group C.

both the arteries and veins, increasing capacitance [10]. These pharmacological properties of milrinone suggest that milrinone can reduce I/R injury. Kume et al. [11] reported that the pretreatment of milrinone protected the liver from warm I/R injury,

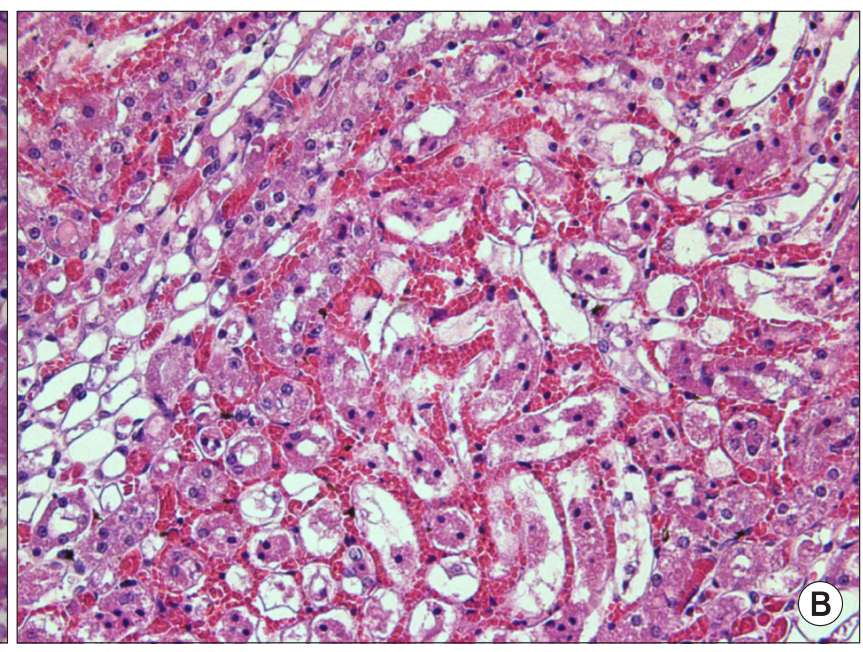

Fig. 2. Representative photomicrographs of the corticomedullary junction of the kidney (light microscope, hematoxylin and eosin staining, magnification $\times 400$ ). (A) Sham-operated mice (group S). (B) I/R injury group (group C). (C) Milrinone treatment group (group M). Severe necrosis of the proximal convoluted tubule, tubular lumen obstruction and impairments, desquamation of tubule cells, severe medullary congestion and hemorrhage in group $\mathrm{C}$. These renal injury findings were improved in group $\mathrm{M}$, compared with group $\mathrm{C}$.

and this pre-treatment mimics the physiological phenomena of ischemic pre-conditioning. Satoh et al. [12] demonstrated that milrinone treatment alleviated warm ischemia-reperfusion induced liver injury, and the activation of cAMP-dependent protein kinase A played a key role in this protection against I/ $\mathrm{R}$ injury. Furthermore, it is reported that milrinone reduced the inflammatory response and improved microcirculation during inflammation $[7,13]$, which suggest that milrinone can reduce I/ R injury effectively.

There are two essential protection mechanisms of milrinone against I/R injury. First of all, milrinone can improve the renal microcirculation in the reperfusion period. Increased c-AMP by milrinone pretreatment can induce endothelium-dependent vasodilation $[14,15]$ and stabilization of the endothelial barrier during ischemia [16]. This can help maintain vascular patency during reperfusion, improving the tissue oxygen supply and preserving the glomerular filtration rate, which leads to the maintenance of the renal function and reduction of tissue injury in the kidney.

Second, c-AMP that is increased by milrinone can reduce the 
A

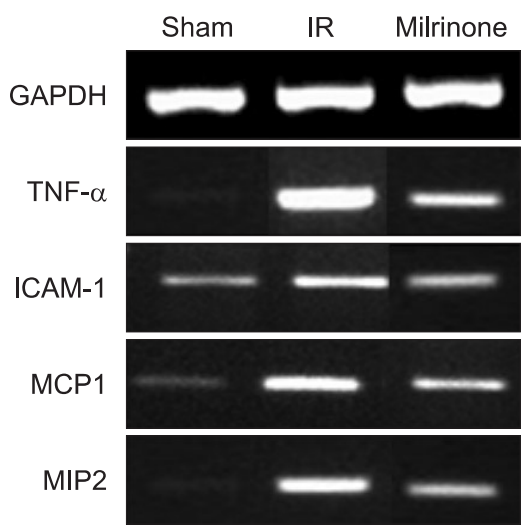

B
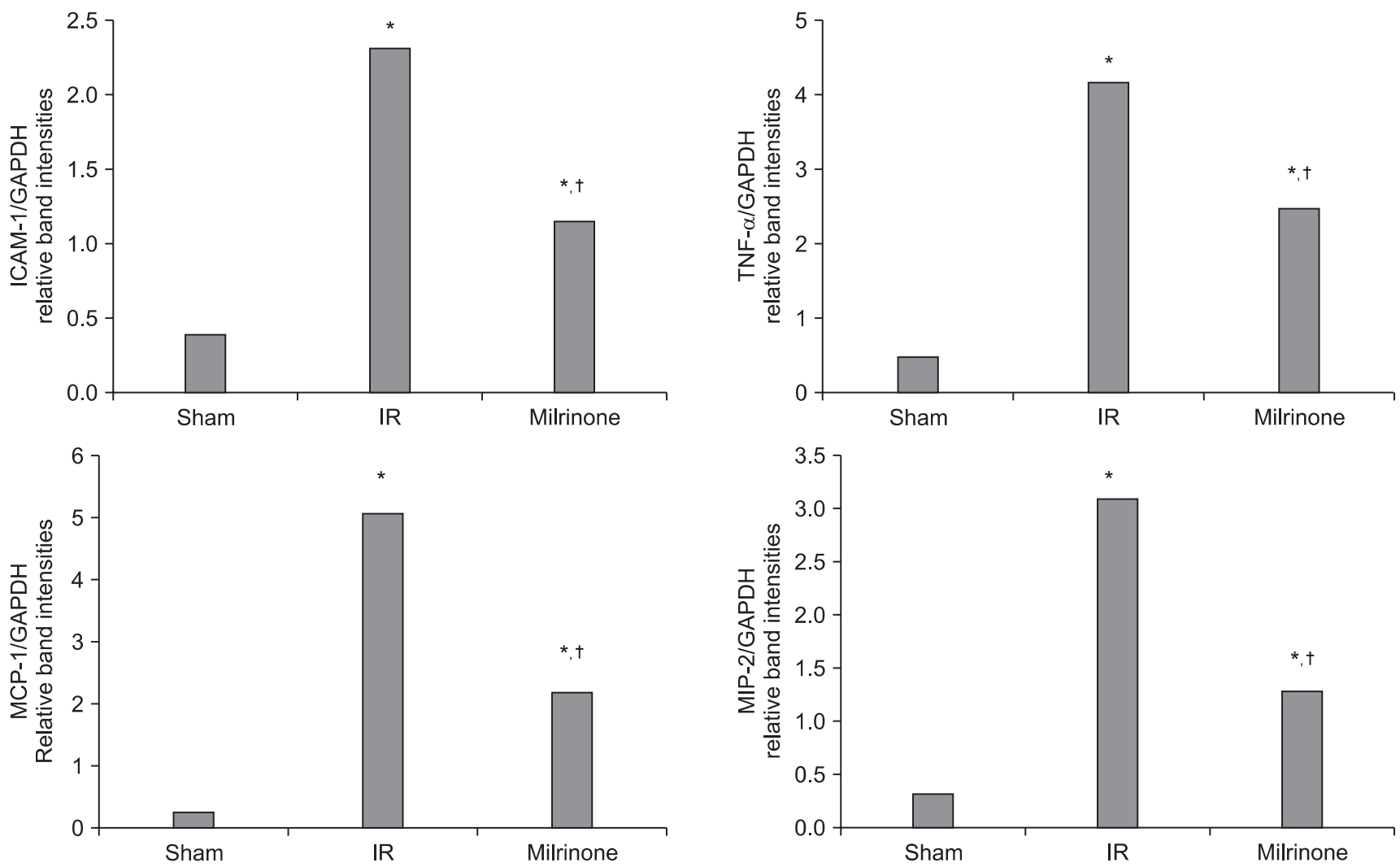

Fig. 4. (A) Representative RT-PCR images for TNF- $\alpha$, ICAM-1, MCP-1, MIP-2 mRNA expression in the sham group (group S), I/R group (group C), and milrinone treatment group (group M). (B) Densitometric quantifications of relative band intensities normalized to GAPDH from RT-PCR reactions for each indicated mRNA. $* \mathrm{P}<0.001$ vs. sham (group $\mathrm{S}, \mathrm{n}=10$ ). ${ }^{\dagger} \mathrm{P}<0.001$ vs. I/R (group $\mathrm{C}, \mathrm{n}=10$ ).

inflammatory response and renal apoptosis. In our study, the milrinone treatment group showed a lower expression of TNF- $\alpha$, which was similar to the study by Semmler et al. [17]. In the reperfusion period, the activation of NF-kB and TNF- $\alpha$ led to an inflammatory response, resulting in up-regulation of vascular endothelial adhesion molecules such as the ICAM-1 and neutrophil chemoattractants $[18,19]$. In addition, TNF- $\alpha$ increases the production of vasopressors, such as platelet-activating factor and endothelin-1 [20]. It leads to an increase of renal vascular permeability, tubular obstruction, and a decreased glomerular filtration rate, resulting in acute tubular necrosis and renal dysfunction [21-23]. However, the decreased expression of TNF-a by milrinone treatment helps reduce renal tissue injury by lowering the inflammatory cascade and maintaining renal function.

In our study, it was found that milrinone pretreatment can cause improvement of kidney function and renal histology. To 
A

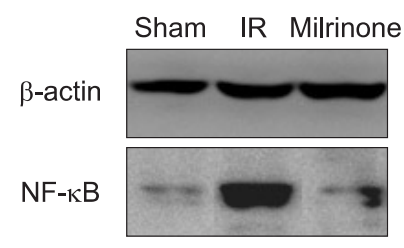

B

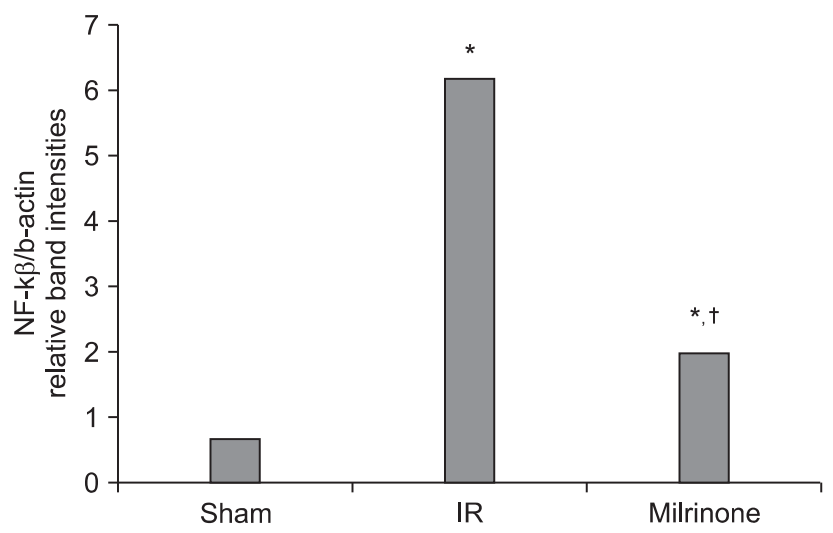

Fig. 5. (A) Representative immunoblots for NF-kB in the sham group (group S), I/R group (group C), and milrinone treatment group (group M). (B) Densitometric quantifications of relative band intensities. $* \mathrm{P}<0.001$ vs. sham (group $\mathrm{S}, \mathrm{n}=10$ ). ${ }^{\dagger} \mathrm{P}<0.001$ vs. I/R (group $\mathrm{C}, \mathrm{n}=10$ ). investigate the molecular mechanism of the protective effects of milrinone in renal $\mathrm{I} / \mathrm{R}$ injury, we evaluated the activation of NF-kB, and expression of TNF- $\alpha$, ICAM-1, MCP-1 and MIP-2 mRNA. Our data demonstrated that the expressions of TNF- $\alpha$ and NF-kB were significantly increased in the renal I/R injury group, which was reversed by milrinone pretreatment.

In the acute inflammatory response, which plays a key role in $\mathrm{I} / \mathrm{R}$ injury, the activation of the TNF- $\alpha / \mathrm{NF}-\mathrm{kB}$ signal pathway is significant. After exposure to cytokines such as TNF- $\alpha$, inflammatory responses can greatly depend on the activation of NF-kB $[24,25]$. In addition, TNF- $\alpha$ is known to be regulated by NF-kB activity [26]. In this study, milrinone treatment caused decreased activation of NF-kB and TNF- $\alpha$, which suppressed the following inflammatory responses.

In conclusion, renal I/ $\mathrm{R}$ injury causes activation of the critical inflammatory cascade, including the activation of NF-kB and inflammatory cytokines such as TNF- $\alpha$ and induction of vascular adhesion molecules (ICAM-1) and neutrophil chemoattractants (MIP-2, MCP-1). Milrinone pretreatment attenuates the renal inflammatory response and activation of $\mathrm{NF}-\mathrm{kB}$, resulting in improvement of renal function and histology.

\section{Acknowledgments}

The Authors wish to acknowledge the financial support of the St. Vincent's hospital, research institute of medical science.

\section{References}

1. Joo JD, Kim DW, Kang YJ, Kim YS, Jeon YS, In JH, et al. Renal protective effects of opposite renal ischemic preconditioning against renal ischemic reperfusion injury in mice. Korean J Anesthsiol 2007; 53: 229-33.

2. Fan H, Sun B, Gu Q, Lafond-Walker A, Cao S, Becker LC. Oxygen radicals trigger activation of NF-kappa B and AP-1 and upregulation of ICAM-1 in reperfused canine heart. Am J Physiol Heart Circ Physiol 2002; 282: H1778-86.

3. Wan F, Lenardo MJ. The nuclear signaling of NF-kB: current knowledge, new insights, and future perspectives. Cell Res 2010; 20 : 24-33.

4. Häcker H, Karin M. Regulation and function of IKK and IKK-related kinases. Sci STKE 2006; 357: re13.

5. Senftleben U, Karin M. The IKK/NF-kB pathway. Crit Care Med 2002; 30(1 Suppl): S18-26.

6. Boswell-Smith V, Spina D, Page CP. Phosphodiesterase inhibitors. Br J Pharmacol 2006; 147(Suppl 1): S252-7.

7. Lanfear DE, Hasan R, Gupta RC, Williams C, Czerska B, Tita C, et al. Short term effects of milrinone on biomarkers of necrosis, apoptosis, and inflammation in patients with severe heart failure. J Transl Med 2009; 7: 67.

8. Nishiki T, Kitada H, Okabe Y, Miura Y, Kurihara K, Kawanami S, et al. Effect of milrinone on ischemic-reperfusion injury in the rat kidney. Transplant Proc 2011; 43: 1489-94.

9. Jablonski P, Howden BO, Rae DA, Birrel CS, Marshall VC, Tange J. An experimental model for assessment of renal recovery from warm ischemia. Transplantation 1983; 35: 198-204.

10. Levy JH, Ramsay J, Bailey JM. Pharmacokinetics and pharmacodynamics of phosphodiesterase-III inhibitors. J Cardiothorac Anesth 1990; 4(Suppl 5): 7-11.

11. Kume M, Banafsche R, Yamamoto Y, Yamaoka Y, Nobling R, Gebhard MM, et al. Dynamic change of post-ischemic hepatic microcirculation improved by a pre-treatment of phosphodiesterase-3 inhibitor, Milrinone. J Surg Res 2006; 136: 209-18.

12. Satoh K, Kume M, Abe Y, Uchinami H, Yakubouski SV, Takahashi T, et al. Implication of protein kinase A for a hepato-protective mechanism of milrinone pretreatment. J Surg Res 2009; 155: 32-9.

13. Craciun EM, Altfelder F, Kuss N, Poeschl J, Ruef P. Anti-inflammatory effects of selected drugs on activated neonatal and adult neutrophils. Scand J Clin Lab Invest 2013; 73: 407-13. 
14. Comerford KM, Lawrence DW, Synnestvedt K, Levi BP, Colgan SP. Role of vasodilator-stimulated phosphoprotein in PKA-induced changes in endothelial junction permeability. FASEB J 2002; 16: 583-5.

15. Schäfer A, Burkhardt M, Vollkommer T, Bauersachs J, Münzel T, Walter U, et al. Endothelium-dependent and -independent relaxation and VASP serines 157/239 phosphorylation by cyclic nucleotide-elevating vasodilators in rat aorta. Biochem Pharmacol 2003; 65 : $397-405$.

16. Qiao J, Huang F, Lum H. PKA inhibits RhoA activation: a protection mechanism against endothelial barrier dysfunction. Am J Physiol Lung Cell Mol Physiol 2003; 284: L972-80.

17. Semmler J, Gebert U, Eisenhut T, Moeller J, Schönharting MM, Alléra A, et al. Xanthine derivatives: comparison between suppression of tumor necrosis factor-alpha production and inhibition of c-AMP phosphodiesterase activity. Immunology 1993; 78: 520-5.

18. Jaeschke H, Hasegawa T. Role of neutrophils in acute inflammatory liver injury. Liver Int 2006; 26: 912-9.

19. Lalor PF, Sun PJ, Weston CJ, Martin-Santos A, Wakelam MJ, Adams DH. Activation of vascular adhesion protein-1 on liver endothelium results in an NF-kappa B-dependent increase in lymphocyte adhesion. Hepatology 2007; 45: 465-74.

20. Bombeli T, Mueller M, Haeberli A. Anticoagulant properties of the vascular endothelium. Thromb Haemost 1997; 77: 408-23.

21. Carden DL, Granger DN. Pathophysiology of ischaemia-reperfusion injury. J Pathol 2000; 190: 255-66.

22. Takada M, Nadeau KC, Shaw GD, Marquette KA, Tilney NL. The cytokine-adhesion molecule cascade in ischemia/reperfusion injury of the rat kidney. Inhibition by a soluble P-selectin ligand. J Clin Invest 1997; 99: 2682-90.

23. McDougal WS. Renal perfusion/reperfusion injuries. J Urol 1988; 140: 1325-30.

24. Lee SO, Jeong YJ, Yu MH, Lee JW, Hwangbo MH, Kim CH, et al. Wogonin suppresses TNF-alpha-induced MMP-9 expression by blocking the NF-kappaB activation via MAPK signaling pathways in human aortic smooth muscle cells. Biochem Biophys Res Commun 2006; 351 : 118-25.

25. Wright JL, Tai H, Wang R, Wang X, Churg A. Cigarette smoke upregulates pulmonary vascular matrix metalloproteinases via TNF-alpha signaling. Am J Physiol Lung Cell Mol Physiol 2007; 292: L125-33.

26. Rodriguez M, Cabal-Hierro L, Carcedo MT, Iglesias JM, Artime N, Darnay BG, et al. NF-kappaB signal triggering and termination by tumor necrosis factor receptor 2. J Biol Chem 2011; 286: 22814-24. 